WellBeing International

WBI Studies Repository

$12-15-2012$

\title{
Nursing Females are More Prone to Heat Stress: Demography Matters When Managing Flying-Foxes for Climate Change
}

\author{
Stephanie T. Snoyman \\ Macquarie University \\ Jasmina Munich \\ Macquarie University \\ Culum Brown \\ Macquarie University
}

Follow this and additional works at: https://www.wellbeingintlstudiesrepository.org/ecoiccha

Part of the Animal Studies Commons, Climate Commons, and the Terrestrial and Aquatic Ecology Commons

\section{Recommended Citation}

Snoyman, S., Muhic, J., \& Brown, C. (2012). Nursing females are more prone to heat stress: Demography matters when managing flying-foxes for climate change. Applied Animal Behaviour Science, 142(1), 90-97.

This material is brought to you for free and open access by WellBeing International. It has been accepted for inclusion by an authorized administrator of the WBI Studies Repository. For more information, please contact wbisr-info@wellbeingintl.org.

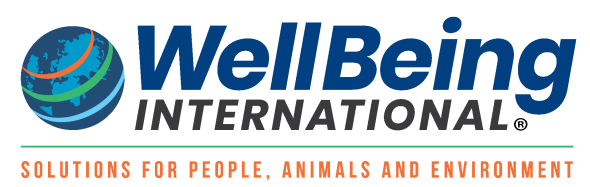




\title{
Nursing Females are More Prone to Heat Stress: Demography Matters When Managing Flying- Foxes for Climate Change
}

\author{
Stephanie Snoyman, Jasmina Munich, Culum Brown \\ Macquarie University
}

\begin{abstract}
KEYWORDS
bat, behaviour, climate change, management, temperature
\end{abstract}

\begin{abstract}
Determining the underlying mechanisms responsible for species-specific responses to climate change is important from a species management perspective. The grey-headed flying-fox, Pteropus poliocephalus, is listed as vulnerable but it also a significant pest species for orchardists and thereby presents an interesting management conundrum. Over the last century, the abundance of the grey-headed flying-fox, P. poliocephalus, in Australia has decreased due to a variety of threatening processes but has increased in abundance in urban areas. These flying-foxes are highly susceptible to extreme heat events which are predicted to increase in the future under climate change scenarios. Exceptionally hot days result in many deaths, the majority of whom are females with dependent young. This study examined the behavioural responses of roosting $P$. poliocephalus to temperature during the summer in their daytime roosts. Bats spent about $30 \%$ of their time resting at low temperatures, however, as temperature increased, fanning displaced resting as the predominant behaviour as bats attempted to cool themselves. Females with nursing young fanned significantly more often $(P=0.001)$ and at a higher rate with rising temperature $(P<0.001)$ than males and females without young (average proportion of time fanning $27 \%, 19 \%$ and $16 \%$, and $4.6,2.8$ and 2.5 for gradient respectively). As a consequence, nursing females also rested less with rising temperature than the other demographic groups $(P<0.001)$. These behavioural indicators suggest that nursing mothers are more vulnerable to heat stress than any other demographic category studied. The data highlight a clear need to monitor the most vulnerable demographic units as part of any species management program.
\end{abstract}

\section{Introduction}

Behavioural monitoring can aid in identifying vulnerable individuals in a managed population since changes in behaviour are the first line of defence when animals respond to stressors such as those induced by urbanisation or climate extremes (Brown, 2012). Behavioural responses to climate extremes vary with life-history strategy and demography, placing some individuals in the population more at risk than others. Variable responses to climate extremes within species are especially evident when particular demographic groups occupy different niches or have varying physiological requirements. For example, male long-tailed bats roost alone and at higher elevations than communal roosting females and have 
higher mortality in extreme weather conditions (Pryde et al., 2005). Thus managers should pay particular attention to the most vulnerable demographic when developing strategic management plans for threatened species, especially in the light of impending weather perturbations resulting from climate change.

Fig. 1. Mean ( $\pm \mathrm{SE})$ annual temperature in Sydney during summer (February) has increased significantly since records began (regression: $F_{1,151}=41.28, P<0.001$ ). Data from the Australian Bureau of Meteorology.

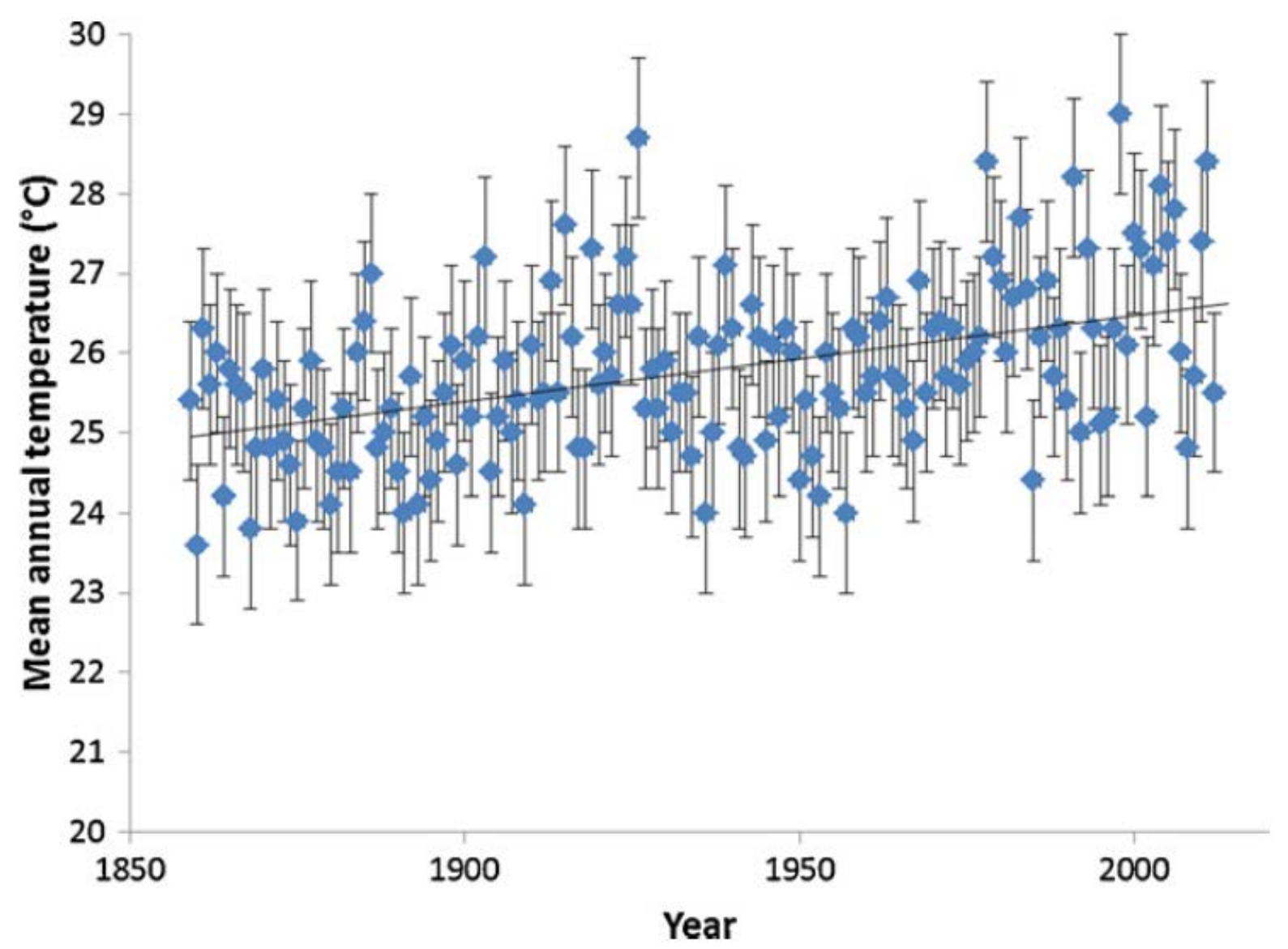

Flying foxes are large fruit bats of key environmental and economic importance but frequently come into conflict with humans (Fujita and Tuttle, 1991). Almost half of the species in the Pteropus genus are listed as threatened (31 of 65 species; IUCN red list, 2010) and four are critically endangered. The grey-headed flying-fox, Pteropus poliocephalus (Temminck, 1825) is one of four species endemic to the east coast of Australia (Hall and Richards, 2000; Webb and Tidemann, 1996) and is listed as vulnerable under the Commonwealth Environment Protection and Biodiversity Conservation Act 1999 (Eby and Lunney, 2002; EPBC, 1999) and the IUCN (IUCN red list, 2010). This species represents a considerable management conundrum. Its distribution coincides with the greatest human population densities and although their population numbers are in decline, bats are increasingly moving into urban areas where they are attracted by year round food sources. Urban roosts can contain tens of thousands of individuals. This process has dramatically increased their exposure to humans and the inevitable conflicts. Many of these roosts are actively managed by community groups. For example, colonies have recently been forcibly evicted from the Melbourne and Sydney Botanical Gardens after the roosting bats caused defoliation of 
significant tree specimens. In other colonies, microsprays have been installed to reduce summer mortality. Even though they are protected in most states and federally, in Queensland this species is considered a significant pest to orchardists and managers can apply for licences to shoot them.

P. poliocephalus has a thermoneutral zone between 19 and $35^{\circ} \mathrm{C}$ (Bartholomew et al., 1964) and choose their roosting habitats based on specific microclimate parameters (Snoyman and Brown, 2010). At high temperatures they are susceptible to heat stress due to their inability to sweat and must employ behavioural strategies to maintain homeostasis including moving into the shade, panting, wing-fanning and licking fur and wing membranes (Bartholomew et al., 1964). Females are known to reject their young when climatic conditions are unfavourable (Luly et al., 2010). A recent paper reported mass deaths of $P$. poliocephalus and Pteropus alecto across a number of roosts during an extreme heat event (Welbergen et al., 2008). Most of the fatalities were dependent young and females. Climate models for the region where P. policephalus occurs predict, and empirical data show, an increase in mean temperatures (Fig. 1) and frequency of extreme weather events (Hughes, 2003) thus potentially placing the species at greater risk.

P. poliocephalus is a useful model for examining the potential implications of climate extremes on species management. The Action Plan for Australian Bats specifically lists climate change as a potential threatening process and calls for further research into the likely consequences on the species' conservation status (Duncan et al., 1999). Here we investigated the behavioural responses of $P$. poliocephalus to natural climatic variation in two roost sites within suburban Sydney during the summer. We aimed to determine if (1) changes in behaviour are correlated with temperature and can therefore be used to predict heat stress events in this species and (2) certain members of the population are more susceptible to heat stress than others. Specifically, we hypothesised that nursing mothers would show more signs of heat stress than other demographic categories and this would explain their overrepresentation in morbidity counts during extreme heat events (Welbergen et al., 2008). Our data are particularly relevant for managing this vulnerable species under future climate change scenarios.

\section{Methods}

Fieldwork was conducted within two permanently occupied roosts in Sydney, New South Wales, Australia; Cabramatta Creek flying-fox Reserve ( $33^{\circ} 54^{\prime \prime} \mathrm{S}, 150^{\circ} 56^{\prime \prime}$ E) and Ku-ring-gai flying-fox Reserve in Gordon ( $33^{\circ} 45^{\prime \prime} \mathrm{S}, 151^{\circ} 09^{\prime \prime} \mathrm{E}$ ). The two reserves were chosen because they represent the extreme variability in roost locations (Parsons et al., 2010), although both are within suburban Sydney. The Cabramatta roost is small $(\mathrm{ca} 2.8 \mathrm{Ha}$ ) and contained along the banks of a tidal creek. The general landscape is flat and the roost is dominated by sheoaks (Casuarine gluca) with a weedy understory. The number of bats in the colony fluctuates between 5000 and 30,000. The Gordon reserve is significantly larger $(14.6 \mathrm{Ha})$ and is contained along a deep, forested gorge. The dominant tree species in the roost are turpentines (Syncapia glomulifera) and blue gums (Eucalyptus globulus). The average number of bats in the reserve is close to 30,000 but can be as high as 70,000. The bats in both roosts are constantly monitored by local conservation groups. Ten data loggers (iButton Hygrochron DS1923, Dallas Semiconductor, Dallas, TX, USA) measuring temperature $\left({ }^{\circ} \mathrm{C}\right)$ were installed at each location in trees containing a large number of roosting bats. All data loggers were set to record at two-hourly intervals. The bats in both roosts tend to utilise all available trees regardless of species identity and many were denuded owing to the roosting activity of the bats (unpublished data). Loggers were attached directly to a circular length of rope which enabled them to be accurately placed in each tree. For ethical reasons, loggers were installed in the winter (July and August) prior to the onset of the critical birthing period.

The breeding cycle of this species is extensive. Mating peaks in autumn and birthing occurs in spring. Behavioural observations were conducted during the summer of 2007-08 and 2008-09 (December- 
February) when females are nursing dependent young and males are establishing and defending territories. We deliberately targeted this time of year because heat stress is most likely to occur in the height of summer. Observations were carried out during the hottest part of the day between 07:00 and 16:00 h (AEST) and were evenly distributed across the summer period. Limited observations were conducted on days in which it rained as activity generally ceased while the bats curled up within their wings (pers. obs.). Upon entering the reserve, the observer took up a position where multiple roost trees in close proximity to a tree containing a data logger were in view. The observer remained still for 20 min to allow the bats to habituate to their presence before sampling began. Instantaneous sampling methods (Martin and Bateson, 1993) were employed to observe individual bats with the aid of $10 \mathrm{~mm} \times 50 \mathrm{~mm}$ binoculars, and the status of the bats noted every $30 \mathrm{~s}$ for a total of half an hour per individual bat resulting in 60 behavioural counts per individual. The most common behaviours observed are listed in Table 1, although a number of other minor behavioural categories were also noted (e.g. flying, social interactions, licking/grooming, panting and out of sight) but they occurred too rarely to analyse. Note that fanning for cooling differs from fanning used by males to broadcast their scent in that in the latter case wings are outstretched. Where possible, three bats were observed simultaneously within a given tree and multiple trees were observed within a day. The three bats chosen had to be in full view of the observer but were otherwise chosen at random. During each observation the sex of the bat, the height in the tree, the presence or absence of sunlight and the time were recorded. Behavioural observations were conducted on individuals located within close proximity (within $25 \mathrm{~m}$ ) to a data logger in order to correlate behaviour with temperature. The closest temperature recording to the mid-point of the observation period was used. No bat was observed more than once on a given day, no roost tree was repeatedly sampled so the protocol allowed for observation of behaviour representative of the colony as a whole. In 2008, 64 bats were observed in Cabramatta and 26 in Gordon. In 2009275 bats were observed at Cabramatta. These observations occurred in 188 different trees. Note that we only collected data from the hotter location in 2009 to maximise our chance of observing heat stress.

Table 1

The three primary behavioural categories of the grey-headed flying-fox.

\begin{tabular}{|ll|}
\hline Behavioural category & Description \\
\hline Alert & $\begin{array}{l}\text { Hanging from a perch, with wing/s outstretched or with head looking away from its wings, } \\
\text { eyes open. }\end{array}$ \\
Fanning & $\begin{array}{l}\text { Hanging from a perch while opening and closing at least one wing in a fanning motion. } \\
\text { Wings held around the body to direct airflow at the body. } \\
\text { Resting }\end{array}$ \\
& $\begin{array}{l}\text { Hanging from a perch with wings wrapped around body, head tucked in towards the wings } \\
\text { and eyes closed. }\end{array}$ \\
\hline
\end{tabular}

\subsection{Statistical analysis}

The data were analysed using general linear models examining the relationship between the log of the counts of the three most common behaviours as the dependent variables (resting, alert and fanning) and temperature as covariate. Because the data were only collected from a single location in 2009 we split the data by location. For Cabramatta data, demographic category and year were independent variables. For the Gordon data, we simply removed year from the analysis since bats were only observed at this location in 2008.

While there is some concern that the behaviour of the three bats observed in the same tree at the same time may not be entirely independent, our results indicate that bat behaviour is primarily driven by local climatic variables, not by the behaviour of those around them. Given this, we consider the potential for a lack of independence in these data to be minimal. We used regression analysis to examine the 
relationship between each of the three primary behaviour categories. The remaining two variables, licking and panting, did not occur very often and were only recorded in 2009. We could not transform these variables to make them suitable for parametric analysis so we used a non-parametric Kruskal Wallis test. The amount of time the bats belonging to each demographic group spent in the sun, the temperature at which they were observed and the height in the tree were all analysed using ANOVA. Data were checked for normality prior to analysis. Post hoc tests were conducted with the use of SPSS 15.0 (SPSS, Inc., Chicago, IL, USA) to further examine the data where appropriate. Bats of unknown sex were excluded from the analysis. Observations were also excluded where the behaviour could not be tied to climate variables due to missing or faulty data loggers. A total of 168 females and 207 males were included in the analysis. Of the females observed, 95 were nursing young.

\section{Results}

In the present study, P. poliocephalus performed three primary behaviour categories in their day time roosts; resting, alert and fanning. In 2008/09 we also recorded incidences of licking and panting which may be indicative of heat stress but these events were rare typically comprising less than $2 \%$ of the time budget. The proportion of time spent on each behavioural category differed between the two bat colonies. Resting accounting for $62 \%$ of the time budget at Gordon and $22 \%$ at Cabramatta. Fanning contributed $5 \%$ and $35 \%$ of the behaviours at Gordon and Cabramatta respectively. Incidences of alert were similar at both locations (ca 25\% of the bats' time). The difference in time budgets between locations in 2008 can be attributed to temperature. The average temperature recorded at Gordon during the observational period was $25.6{ }^{\circ} \mathrm{C}$, whereas at Cabramatta it was $30.3^{\circ} \mathrm{C}$. Hence we concentrated on the hotter location in 2009.

Fig. 2. The estimated marginal means ( $\pm \mathrm{SE}$ ) of the proportion of time grey-headed flying-foxes spent performing the three most common behavioural patterns in the Cabramatta reserve at $30.3^{\circ} \mathrm{C}$.

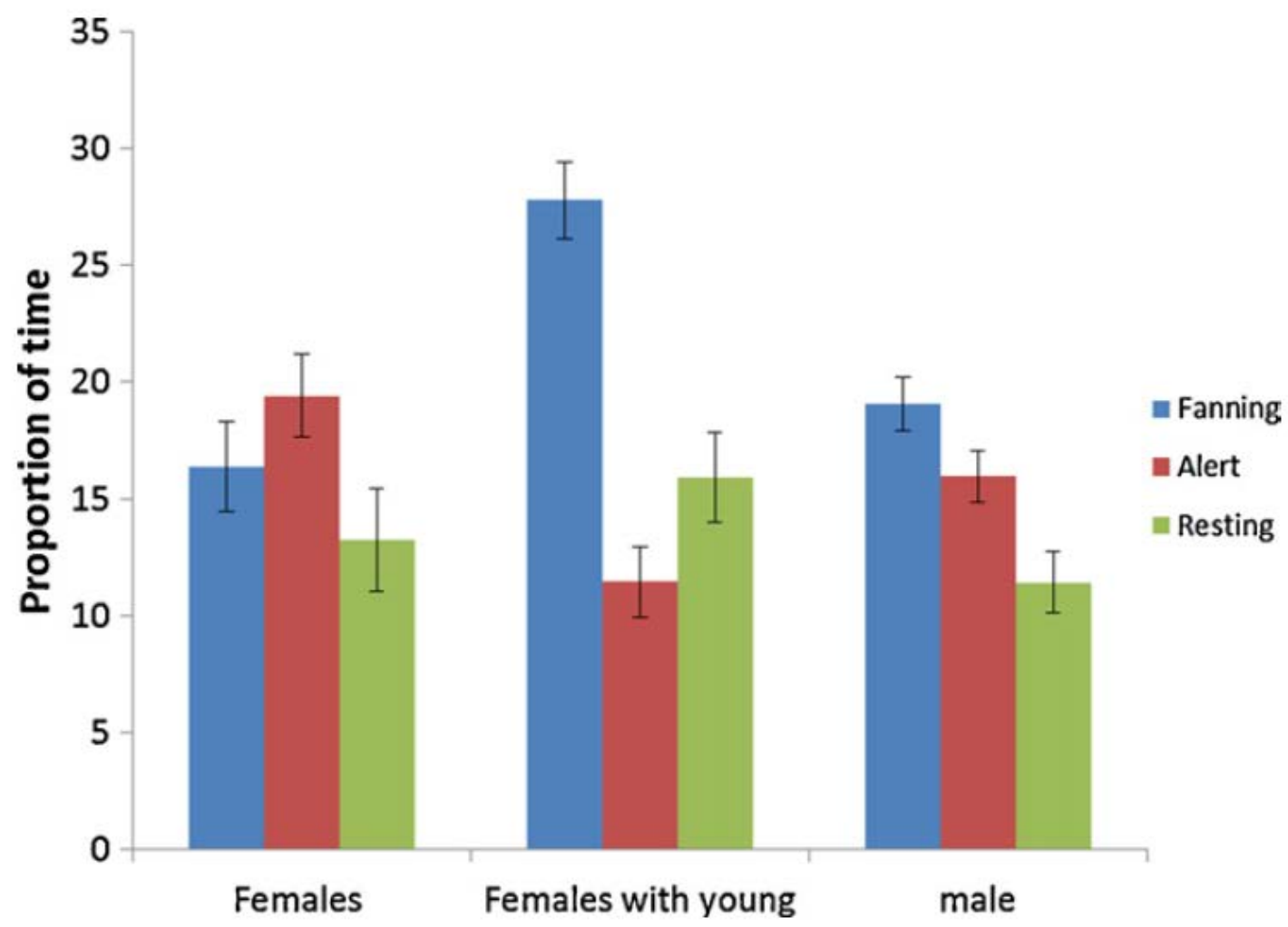




\subsection{Cabramatta}

Analysis of the fanning data from Cabramatta found significant effects of temperature (ANCOVA: $F_{1,333}=$ 294.797, $P<0.001)$, demographic category $\left(F_{2,333}=6.775, P=0.001\right)$ and, more importantly, a significant interaction between demographic category and temperature $\left(F_{2,333}=9.830, P<0.001\right)$. Year had no significant effect, nor did it interact with any other variables $(P>0.3$ in all cases). Post hoc analysis revealed that females with young fanned more than all other demographic groups (Fisher's PLSD: $P<$ 0.001 and 0.013 for females without young and males respectively) and males fanned more often than females $(P=0.006$; Fig. 2). The average proportion of time fanning for females with young, males and females without young was $27 \%, 19 \%$ and $16 \%$ respectively. In general, the amount of fanning displayed by the bats increased with temperature, but females with young showed the greatest rate of increase (Fig. 3). P. poliocephalus started fanning to cool themselves at temperatures exceeding $23{ }^{\circ} \mathrm{C}$ and the incidence of fanning behaviour rapidly increased at temperatures over $30{ }^{\circ} \mathrm{C}$. The rate of fanning increases as temperature increased for females with young, males and females without young was 4.6, 2.8 and 2.5 respectively. To illustrate this interaction with temperature, the data was split into observations that occurred below $25{ }^{\circ} \mathrm{C}$ and those above $30^{\circ} \mathrm{C}$. The results show a significant sex by temperature bracket interaction (ANOVA: $F_{2,224}=5.136, P=0.006$ ). Post hoc test shows no difference between demographic categories when the temperature was less than $25{ }^{\circ} \mathrm{C}(P=0.293)$ but a highly significant difference when temperatures are above $30^{\circ} \mathrm{C}(P<0.001$; Fig. 4).

Fig. 3. The proportion of time grey-headed flying-foxes spent fanning in their daytime roosts at Cabramatta as a function of temperature.

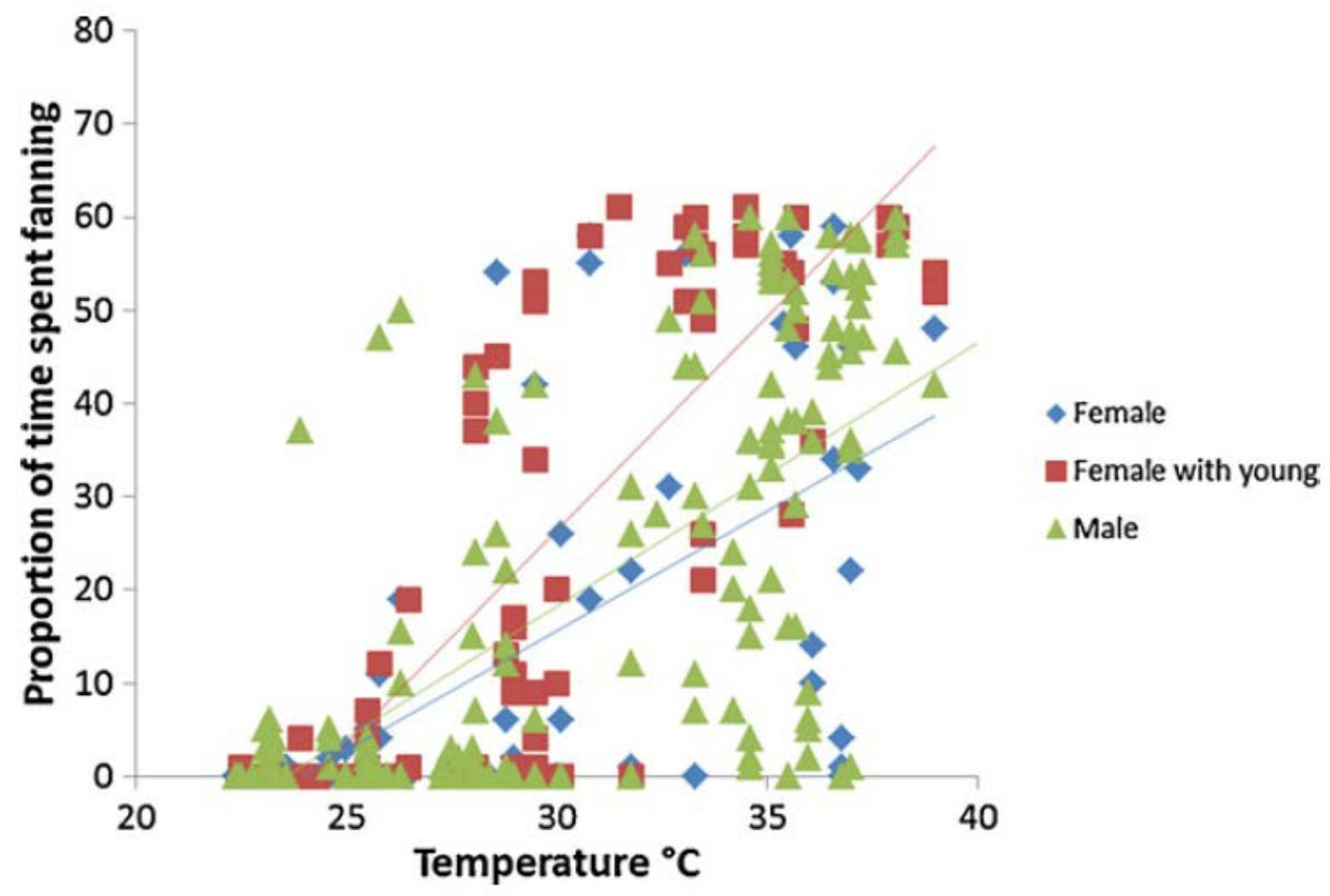


Fig. 4. The proportion of time grey-headed flying-foxes spent fanning in their daytime roosts at Cabramatta when temperatures were less than $20^{\circ} \mathrm{C}$ or greater than $30^{\circ} \mathrm{C}$.

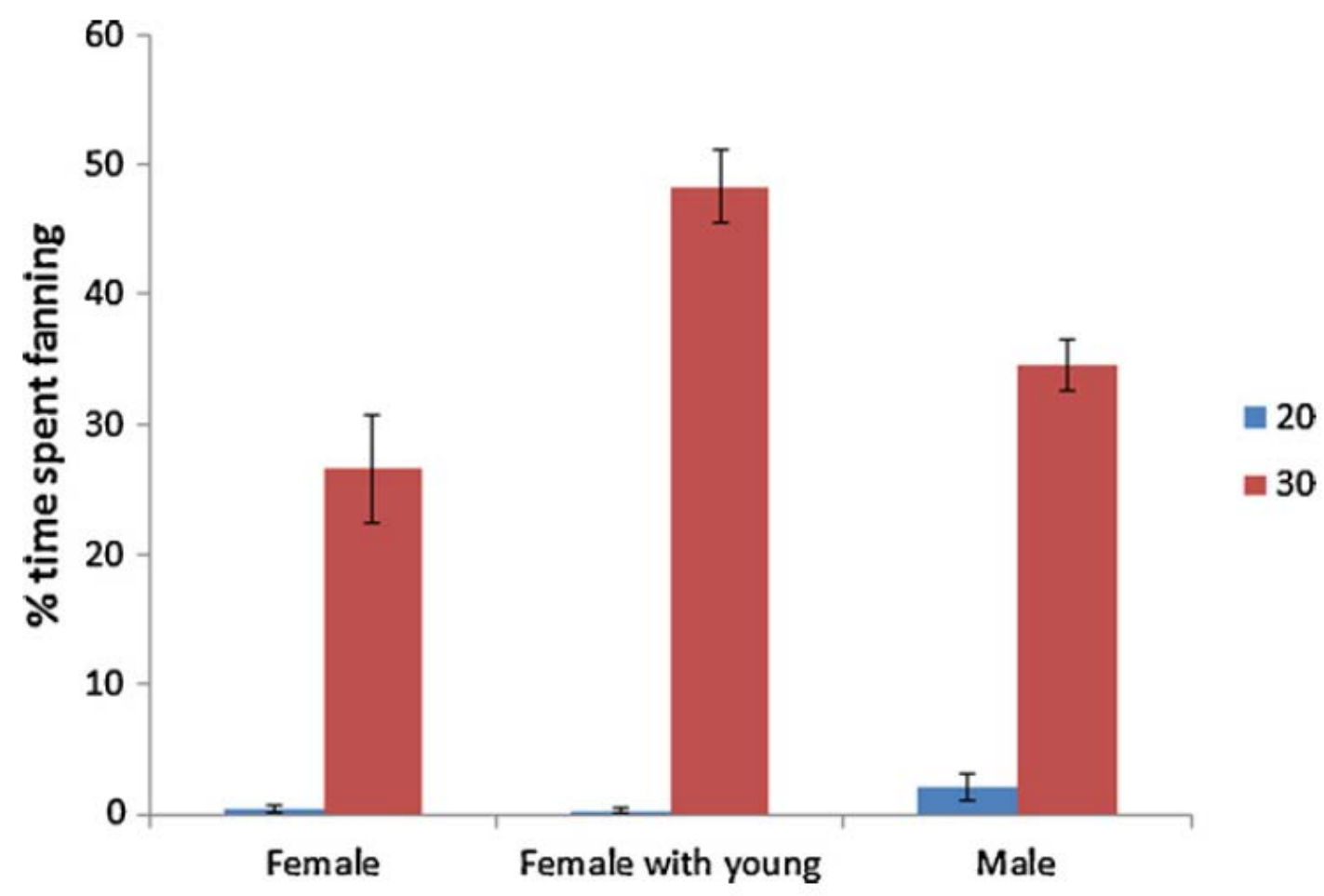

The amount of time bats spent alert decreased significantly with temperature $\left(F_{2,332}=72.411, P<0.001\right)$. Although there was no overall difference between the three demographic categories $\left(F_{2,332}=0.334, P=\right.$ 0.717), post hoc analysis revealed that females without young spent more time alert than any other demographic $(P<0.001$ and $P=0.01$ for females with young and males respectively; Fig. 2$)$. There was no difference between males and females with young. Year had no influence on the data $(P>0.1$ in all instances) and there was no significant interaction between demographic category and temperature $\left(F_{2,332}=0.39, P=0.677\right)$.

Significant differences between demographic groups were also revealed in the time spent resting (ANCOVA: $F_{2,333}=6.238, P=0.002$ ) and it was highly influenced by temperature (ANCOVA: $F_{1,333}=$ 55.235, $P<0.001$ ). The analysis revealed a slight difference between years (ANCOVA: $F_{1,333}=3.875, P=$ 0.05 ) but year did not interact with any other variable $(P>0.5$ in all cases). A significant interaction between demographic category and temperature was observed $\left(F_{2,333}=5.294, P=0.005\right)$ indicating that females with young reduced the time spent resting as temperature increased more rapidly than the other demographic groups (Fig. 5). Post hoc analysis revealed that females with young spent the most time resting, spending more time resting than males $(P=0.006)$ but did not differ significantly from females without young $(P=0.289)$. Nor was there a difference between males and females without young $(P=$ $0.195 ;$ Fig. 2). In general, the amount of time resting decreased with increasing temperature.

Correlation coefficients ranged from 0.192 to 0.545 showing that the prevalence of these three primary behaviours were all highly correlated with one another $(P<0.001$ in all cases). As the amount of fanning increased with temperature, the other two behaviours decreased. 


\subsection{Gordon}

Data for Gordon had to be log transformed prior to analysis. Analysis revealed a significant effect of temperature on the time spent fanning $\left(F_{1,30}=6.817, P=0.014\right)$, alert $\left(F_{1,30}=9.977, P=0.003\right)$ and resting $\left(F_{1,30}=4.990, P=0.033\right)$, but owing to the relatively small sample size no further effects were found.

Fig. 5. The proportion of time grey-headed flying-foxes spent resting in their daytime roosts at Cabramatta as a function of temperature.

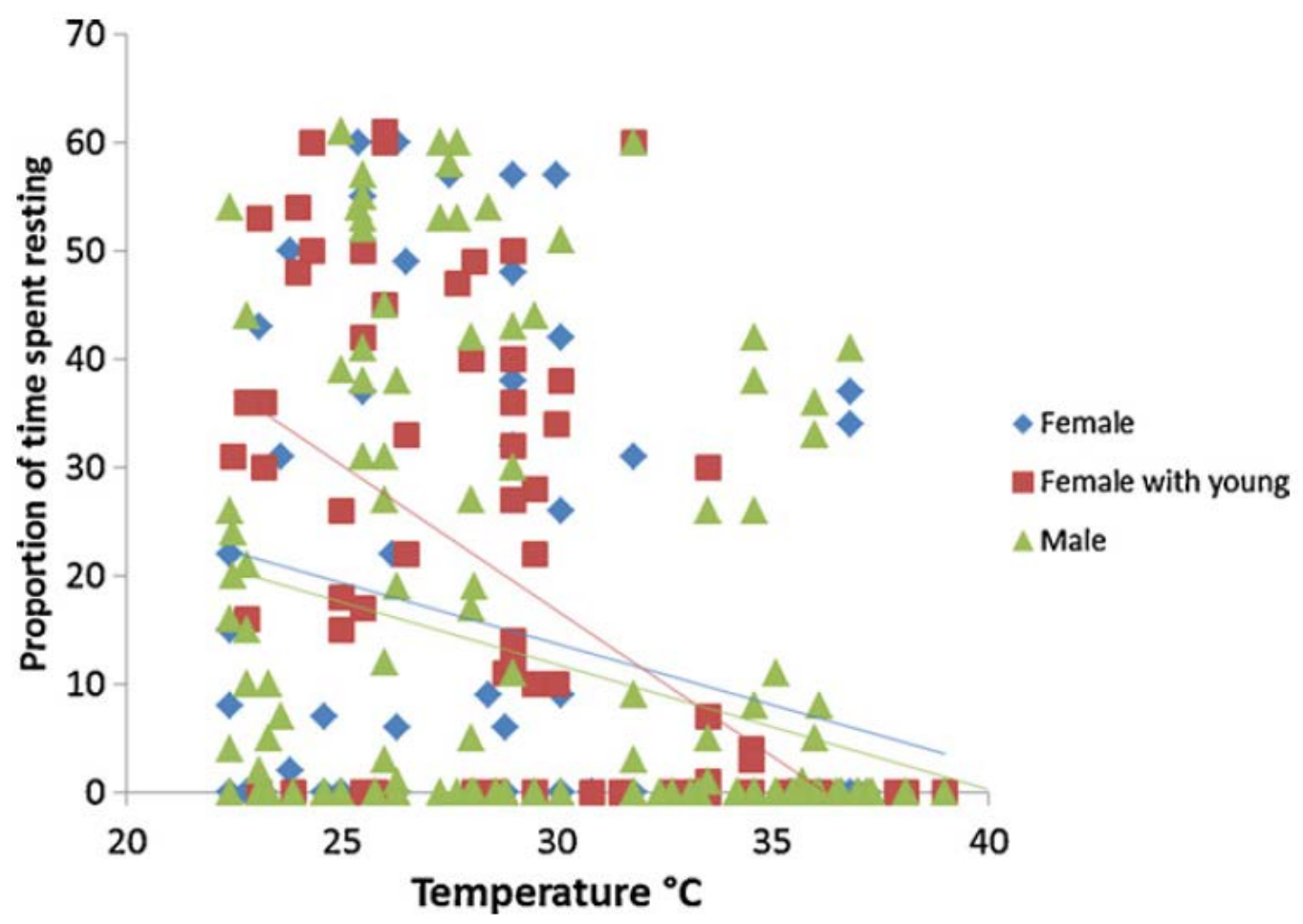

Panting only ever occurred at temperatures over $35^{\circ} \mathrm{C}$ and is indicative of heat stress (Welbergen et al., 2008). Analysis of the data over $35^{\circ} \mathrm{C}$ using Kruskal Wallis revealed no significant differences between sexes $(H=2.612, P=0.271)$. Licking, on the other hand, has been postulated to aid evaporative cooling, however, this behaviour occurred at all temperatures and was probably associated with general grooming since we did not attempt to distinguish between licking of various body parts. Kruskal Wallis analysis again revealed no differences between sexes in this behaviour $(H=0.431, P=0.806)$.

Data from 2008 revealed that females with young tended to spend more time in the sun than other bats (ANOVA: $F_{2,97}=2.839, P=0.063$ ) and consequently, they were observed in roost locations that had higher temperature than both the males and females without young (ANOVA: $F_{2,97}=6.844, P=0.002$; Fisher's PLSD: $P=0.0007$ and 0.017 respectively). All demographic groups roosted the same height in the trees (ANOVA: $F_{2,97}=1.878, P=0.174$ ). 


\section{Discussion}

Our results show that behavioural observations are a useful tool for monitoring the response of vulnerable species to climate variation. The initiation of certain behaviours can provide an early warning to managers and identify particularly vulnerable individuals or demographic groups. Such information can be fed directly into management action and used to modify existing models of species responses to future climate change scenarios.

The time budget of $P$. poliocephalus in their daytime roosts during the summer was dominated by three behavioural categories: resting, alert and fanning, the relative frequency of which depended critically on prevailing temperature and demography. The time budget became saturated with incidences of fanning at the expense of resting as temperature increased and bats attempted to maintain homeostasis. Importantly, females with young showed the greatest responses to increasing temperatures, suggesting that they are more vulnerable to high temperatures than other demographic groups. This suggests that planned conservation intervention management in this species should specifically target nursing females perhaps by using them as the stress indicator demographic.

In general, resting predominated in temperatures ranging from 17 to $30{ }^{\circ} \mathrm{C}$, corresponding to the lower range of the reported thermoneutral zone for this species (Bartholomew et al., 1964). Rates of fanning were strongly positively correlated with temperature (Fig. 3). Wing-fanning contributes to thermoregulation by forced convection (Laburn and Mitchell, 1975) and is relatively energetically taxing. Fanning, however, undoubtedly has an immediate impact on individual fitness during summer by reducing body temperature. Females with young showed the greatest rate of change in fanning behaviour as temperature increased. At low temperatures there was little difference between the demographic groups but it is apparent that they are especially vulnerable to heat stress since they fan more often than all other demographic groups at high temperatures (Fig. 3). The increases in fanning largely occurred at the expense of resting and the rate of decrease in resting with increasing temperature was also greatest for nursing mothers (Fig. 4). This suggests that nursing mothers are not only expending more energy but they are also losing valuable recovery time during the daily resting period. All in all, these observations corroborate previous accounts of mortality rates during extreme heat events which are dominated by dependent young and lactating females (Welbergen et al., 2008).

Licking and panting did not vary between the three demographic groups. We found that licking occurred at all temperatures and was probably indicative of general grooming behaviour rather than a response to heat stress. While we did not differentiate between wrist licking and licking of other body parts, it is likely that the temperatures did not reach critical levels during the observation period for the bats to rely on licking as a thermoregulatory mechanism as this response is reserved when temperatures are close to their lethal limit (Licht and Leitner, 1967). Likewise panting did not vary between bats. At very high temperatures, all bats resort to panting in an effort to reduce their heat loads and this is part of a predictable series of events in this species that culminates in death once lethal limits are breached (Welbergen et al., 2008).

There are several possible explanations as to why females with young are more sensitive to heat. Firstly, mothers spend a significant proportion of their time nursing their young. Thus both mother and offspring may retain significantly more metabolic heat through clustering. Clustering may moderate the extent of heat loss through radiation (Davis et al., 1962), thereby warming the surrounding area (Willis and Brigham, 2007). Hence, a mother clustering with her offspring would display behavioural modifications related to thermoregulation at a lower temperature than solitary individuals. Secondly, nursing females are likely to have increased metabolic rates associated with lactation and are thereby more susceptible to heat stress (Brody, 1974). In addition, previous studies on bats suggest that nursing females may 
deliberately choose warm locations to roost in order to minimise the metabolic costs associated with lactation (Law and Chidel, 2007) or maximise juvenile development (Lausen and Barclay, 2006; Zahn, 1999). Our observations during the relatively mild summer of 2008 suggest that nursing mothers tended to be in the sun more often than the shade while the reverse was true for males and females without young. This increased exposure to solar radiation corresponded to females with young occupying locations within a roost that were $3{ }^{\circ} \mathrm{C}$ warmer than all other demographic groups. Alternatively, it may be that because females are smaller than males, they are forcibly evicted from preferred roosting locations. Perhaps females with young are less able to defend their preferred roosting perches or deliberately move away from conspecifics to reduce competitive interactions. In either scenario, nursing mothers are clearly exposed to higher temperatures than males and females without young and this factor further increases their susceptibility to mortality during extreme heat events.

Both historical data show (Fig. 1) and models predict (CSIRO and ABoM, 2007; Hughes, 2003) that mean temperatures and the frequency of extreme heat events are increasing in Australia. In general, the frequency of extreme heat events increases with latitude in eastern Australian (Australian Bureau of Meteorology; Dury, 1972). On average, both Melbourne and Adelaide have considerably more days per year exceeding $35{ }^{\circ} \mathrm{C}$ (9 and 17 respectively) than either Sydney or Brisbane (3.5 and 1 respectively; $A B O M)$. This north-south differential will be further exacerbated under future climate change scenarios (CSIRO and ABoM, 2007). This situation has considerable implications for a number of threatened endemic species in Australia including P. poliocephalus. If this species is pushed to higher latitudes in response to increased mean temperatures, paradoxically this will expose them to a greater frequency of extreme heat events (Welbergen et al., 2008). Thus, its ability to cope with climate change at higher latitudes will be constrained primarily by the high morbidity of nursing mothers on very hot days.

Some studies have suggested that flora and fauna can potentially adapt to climate change assuming that suitable genetic variability exists within the population and the generation time is short enough to respond (Dobzhansky, 1947). However, this is unlikely to occur in long lived mammals with slow reproduction. P. poliocephalus may have some potential to respond to climate change by rapid shifts in distribution owing to its generalist diet and great potential for long-distance dispersal. Indeed a range of historical data shows that this and other species have survived previous climate induced bottlenecks during the last glacial maximum (Hof et al., 2011; Luly et al., 2010). However, this was in the absence of other anthropogenic threats such as land clearing and urbanisation which further complicate species' ability to move through the landscape (Parris and Hazell, 2005). High mobility, however, may actually work against some species in terms of their heat stress adaptability because it results in genetic mixing between individuals occupying the centre and the extremities of the distribution. Less mobile species tend to evolve greater thermal tolerances at the extremities of the distribution owing to intense selective pressures. Genetic analysis of bats in roosts along the entire coast of Australia, coupled with radio tagging data suggest that P. poliocephalus is a single panmictic population (Baldwin et al., unpublished data; Spencer et al., 1991; Tidemann and Nelson, 2004; Webb and Tidemann, 1996). Nevertheless, further observations of behavioural responses to climactic variables across the species range may reveal considerable individual variation in behavioural plasticity (Hof et al., 2011).

\section{Conclusion}

Our results clearly demonstrate that particular demographic groups within a species can be more sensitive to extreme weather events and this has serious implications for conservation management of threatened species as a whole, particularly for those species where critical life-cycle stages prove to be most vulnerable to climatic perturbation. Future research should focus on identifying those factors that are likely to be responsible for observed species level responses to climate change by focusing at a finer 
scale (e.g. demographic groups, alternative life-history strategies etc.) than that commonly employed to date.

\section{Acknowledgements}

A special thanks to the Gordon and Cabramatta bat conservation groups without whom this project could not have preceded. C. Brown was supported by an Australian Research Fellowship from the Australian Research Council.

\section{References}

Bartholomew, G.A., Leitner, P., Nelson, J.E., 1964. Body temperature, oxygen consumption and heart rate in three species of Australian flying-fox. Physiol. Zool. 37, 179-198.

Brody, S., 1974. Bioenergetics and Growth: With Special Reference to the Efficiency Complex in Domestic Animals. Collier Macmillan, London.

Brown, C., 2012. Experience and learning in changing environments. In: Wong, B., Candolin, U. (Eds.), Behavioural Responses to a Changing World. Oxford University Press, Oxford, pp. 46-62.

CSIRO and ABoM, 2007. Climate change in Australia. Technical Report 2007. http://www.climatechangeinaustralia.gov.au/resources.php

Davis, R.B., Herreid, C.F., Short, H.L., 1962. Mexican free-tailed bats in Texas. Ecol. Monogr. 32, 311346.

Dobzhansky, T.H., 1947. A response of certain gene arrangements in the third chromosome of Drosophila pseudoobscura to natural selection. Genetics 32, 142-160.

Duncan, A., Baker, G.B., Montgomery, N., 1999. The Action Plan for Australian Bats. Environment Australia, Canberra.

Dury, G.H., 1972. High temperature extremes in Australia. Ann. Assoc. Am. Geogr. 62, 388-400.

Eby, P., Lunney, D., 2002. Managing the grey-headed flying-fox Pteropus poliocephalus as a threatened species: a context for the debate. In: Eby, P., Lunney, D. (Eds.), Managing the Grey-Headed Flying-Fox as a Threatened Species in NSW. Royal Zoological Society of New South Wales, Sydney, pp. 1-15.

EPBC, 1999. Environmental Protection and Biodiversity Conservation Act. Australian Government Department of the Environment, Water, Heritage and the Arts.

Fujita, M.S., Tuttle, M.D., 1991. Flying foxes (Chiroptera: Pteropodidae): threatened animals of key ecological and economic importance. Conserv. Biol. 5, 455-463.

Hall, L.S., Richards, G., 2000. Flying Foxes: Fruit and Blossom Bats of Australia. University of New South Wales Press, Sydney.

Hof, C., Levinsky, I., Araújo, M.B., Rahbek, C., 2011. Rethinking species' ability to cope with rapid climate change. Glob. Change Biol. 17, 2987-2990. 
Hughes, L., 2003. Climate change and Australia: trends, projections and impacts. Austral Ecol. 28, 423443.

IUCN, 2010. IUCN Red List of Threatened Species. Version 2010.1. www.iucnredlist.org

Lausen, C.L., Barclay, R.M.R., 2006. Benefits of living in a building: big brown bats (Eptesicus fuscus) in rocks versus buildings. J. Mammal. 87, 362-370.

Law, B.S., Chidel, M., 2007. Bats under a hot tin roof: comparing the microclimate of eastern cave bat (Vespadelus troughtoni) roosts in a shed and cave overhangs. Aust. J. Zool. 55, 49-55.

Laburn, H.P., Mitchell, D., 1975. Evaporative cooling as a thermoregulatory mechanism in the fruitbat, Rousettus aegyptiacus. Physiol. Zool. 21, 195-202.

Licht, P., Leitner, P., 1967. Physiological responses to high environmental temperatures in three species of microchiropteran bats. Comp. Biochem. Physiol. A 22, 371-387.

Luly, J.G., Blair, D., Parsons, J.G., Fox, S., VanDerWal, J., 2010. Last glacial maximum habitat change and its effects on the grey-headed flying-fox (Pteropus poliocephalus Temminck 1825). In: Haberle, S.G., Stevenson, J., Prebble, M. (Eds.), Altered Ecologies: Fire, Climate and Human Influence on Terrestrial Landscapes, Terra Australis. ANU E-Pres, Canberra, pp. 83-100.

Martin, P., Bateson, P., 1993. Measuring Behaviour: An Introductory Guide, 2nd edn. Cambridge University Press, Cambridge.

Parris, K.M., Hazell, D.L., 2005. Biotic effects of climate change in urban environments: the case of the grey-headed flying-fox (Pteropus poliocephalus) in Melbourne, Australia. Biol. Conserv. 124, 267-276.

Parsons, J.G., Van der Wal, J., Robson, S.K.A., Shilton, L.A., 2010. The implications of sympatry in the spectacled and grey headed flying-fox, Pteropus conspicillatus and P. poliocephalus (Chiroptera: Pteropodidae). Acta Chiropterol. 12, 301-309.

Pryde, M.A., O'Donnell, C.F.J., Barker, R.J., 2005. Factors influencing survival and long-term population viability of New Zealand long-tailed bats (Chalinolobus tuberculatus): implications for conservation. Biol. Conserv. 126, 175-185.

Snoyman, S., Brown, C., 2010. Microclimate preferences in the grey-headed flying fox in the Sydney region. Aust. J. Zool. 58, 376-383.

Spencer, H.J., Palmer, C., Parry-Jones, K., 1991. Movements of fruit bats in eastern Australia determined by using radio tracking. Wildl. Res. 18, 463-468.

Tidemann, C.R., Nelson, J.E., 2004. Long-distance movements of the grey-headed flying fox (Pteropus poliocephalus). J. Zool. 263, 141-146.

Webb, N.J., Tidemann, C.R., 1996. Mobility of Australian flying-foxes, Pteropus spp. (Megachiroptera): evidence from genetic variation. Proc. R. Soc. Lond. B: Biol. Sci. 263, 497-502.

Welbergen, J.A., Klose, S.M., Markus, N., Eby, P., 2008. Climate change and the effects of temperature extremes on Australian flying-foxes. Proc. R. Soc. Lond. B: Biol. Sci. 275, 419-425, http://dx.doi.org/10.1098/rspb. 2007.1385. 
Willis, C.K.R., Brigham, R.M., 2007. Social thermoregulation exerts more influence than microclimate on forest roost preferences by a cavity-dwelling bat. Behav. Ecol. Sociobiol. 62, 97-108.

Zahn, A., 1999. Reproductive success, colony size and roost temperature in attic-dwelling bat Myotis myotis. J. Zool. 247, 275-280. 